\title{
Manufacturing Process and Characterization by Dilatometry and Differential Thermal Analysis of X38CrMoV5-1 Steel Parts
}

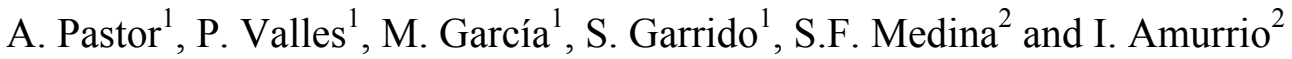 \\ ${ }^{1 .}$ Department of Materials and Structures, National Institute of Aerospace Technology (INTA), \\ Torrejón de Ardoz, Spain. \\ ${ }^{2}$ National Centre for Metallurgical Research (CENIM-CSIC), Madrid, Spain.
}

The usual mechanical properties of martensitic steels are strongly linked to the complex microstructure obtained after heat treatment, which is generally performed to achieve good hardness and tensile strength with acceptable ductility. In the present work, X38CrMoV5-1 (AISI H11-1) steel, classed as a hot-work tool steel with many applications, has been studied from the viewpoint of phase transformations and its manufacturing process.

Parts are often manufactured by die-casting followed by quenching and tempering and the microstructure obtained is highly sensitive to the process. Besides slight changes in chemical composition can have a huge impact on mechanical properties, so the amount and nature of alloying elements must be controlled because of their effect on precipitation of secondary carbides and their modification of tempering kinetics. [1-5]

Previous studies on this steel have shown the optimal heat treatment to obtain an acceptable microstructure that guarantees the behaviour in service. It consists on an annealing at $780^{\circ} \mathrm{C} / 1$ hour, followed by a quenching at $1020^{\circ} \mathrm{C} / 1$ hour, and finally a double tempering at $580^{\circ} \mathrm{C} / 2$ hours [6].

In Figures 1 and 2, it is possible to observe two optical micrographs where a huge difference in microstructure is shown due to a different heat treatment application.

Microstructural defects can lead to early failure of many parts at the service temperature as a consequence of the casting process. For this reason, the authors have studied rolling as an alternative manufacturing process. In this work, mechanical properties of die casting and laminated parts will be compared, showing that these last parts present better toughness that the cast ones.

An extensive characterization of die casting microstructure using dilatometry and differential thermal analysis (DTA) techniques was carried out to study phase transformation during cooling and the CCT diagram was obtained and showed in Figure 3, to determine the cooling rates at which martensitic transformation is achieved $(>0,1 \mathrm{~K} / \mathrm{s})$.

References:

[1] Pastor A. et al., submitted to Engineering Failure Analysis (2014).

[2] Michaud P., et al. Acta Materalia, 55 (2007) p. 4877.

[3] Mebarski N., et al. Materials Science and Engineering A, 387-389 (2004) p. 171.

[4] Delagnes D., et al. Materials Science and Engineering A, 394 (2005) p. 435

[5] ASM Handbook, Volume 9: Metallography and Microstructures. Vander Voort G.F., p. 664.

[6] Valles, et al. Conference Proceedings "At the Frontiers of Science", University of Tarragona, Spain (2013). 


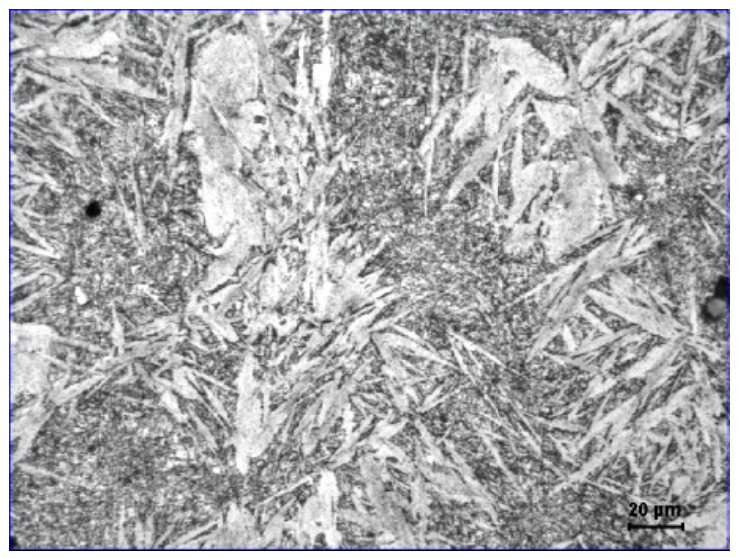

Figure 1. Optical micrograph of brittle microstructure obtained after inadequate heat treatment, consisting in Widmanstätten ferrite in a martensite matrix.

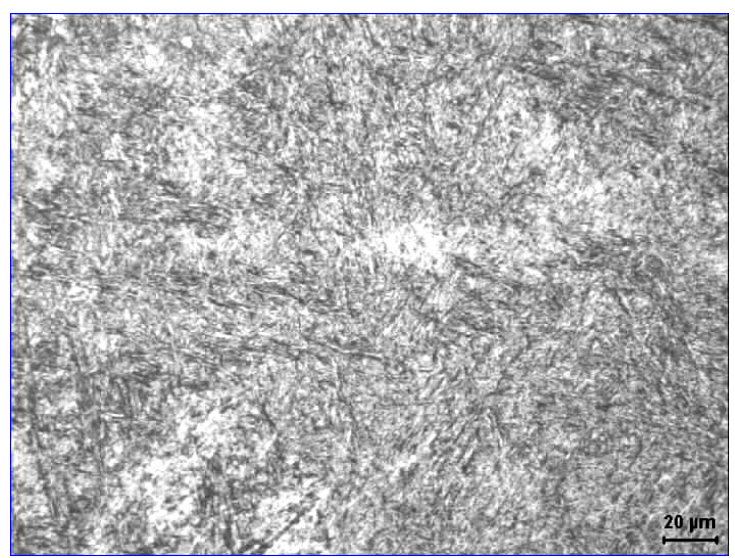

Figure 2. Optical micrograph of acceptable microstructure obtained after optimized heat treatment, consisting in tempered martensite.

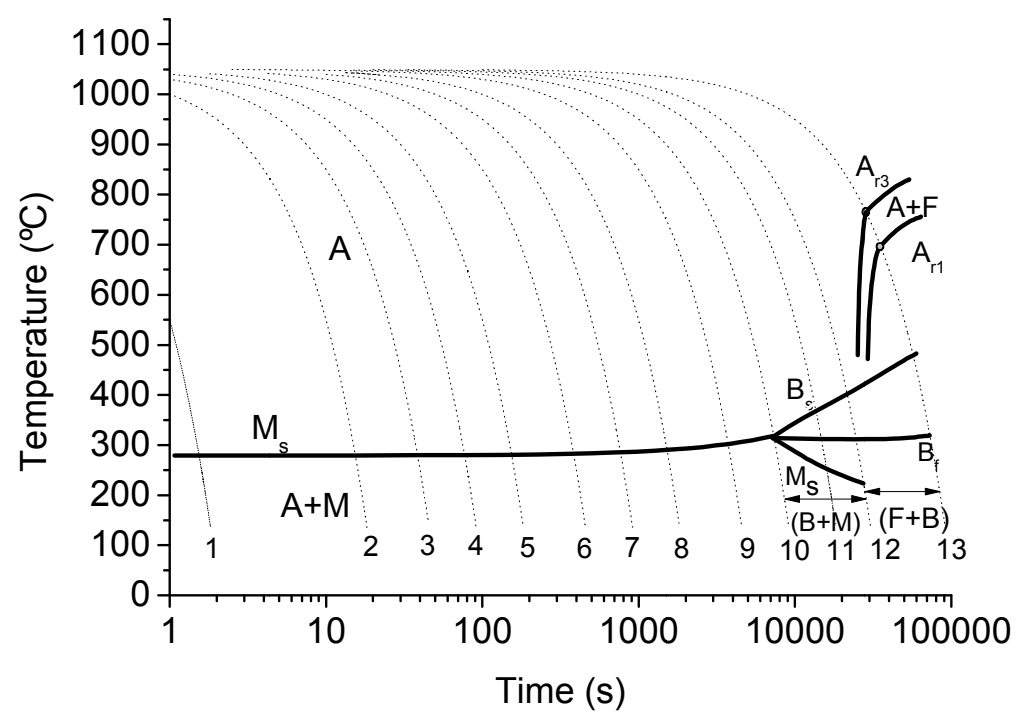

Figure 3. CCT Diagram of X38CrMoV5-1 steel [1]. 